\title{
The Changing Concepts regarding the Mediterranean Fever Gene (MEFV): Toward a Spectrum of Pyrin-Associated Autoinflammatory Diseases (PAAD) with Variable Heredity
}

Guilaine Boursier, PharmD, $\mathrm{PhD}^{1}$, Veronique Hentgen, $\mathrm{MD}^{2}$, Guillaume Sarrabay, $\mathrm{MD}^{3}$, Isabelle KonéPaut, $\mathrm{MD}^{4}$, Isabelle Touitou, MD, $\mathrm{PhD}^{5 *}$

1: Department of Medical Genetics, Rare Diseases and Personalized Medicine, CHU Montpellier, Montpellier, France

2: Department of general pediatrics, $\mathrm{CH}$ Versailles, CEREMAIA, France

3: Stem cells, Cellular plasticity, Regenerative medicine and Immunotherapies, INSERM, University of Montpellier, Department of Medical Genetics, Rare Diseases and Personalized Medicine, CEREMAIA, CHU Montpellier, Montpellier, France

4: University Paris Sud-Saclay, UVSQ, Kremlin Bicetre, France; AP-HP, CHU de Bicetre, Pediatric Rheumatology, CEREMAIA, Le Kremlin Bicetre, France.

$5 *$ Corresponding author: I Touitou, Stem cells, cellular plasticity, regenerative medicine and immunotherapies, INSERM, University of Montpellier, Department of Medical Genetics, Rare Diseases and Personalized Medicine, CEREMAIA, CHU Montpellier, Montpellier, France

Isabelle.touitou@inserm.fr

Tel: +33467335859

Supported by the French Ministry of Health. The authors declare no conflicts of interest.

Key words: FMF, autoinflammatory disorder, PAAD, PAAND

\section{Abbreviations and acronyms:}

IL-1: interleukin 1

FMF: Familial Mediterranean fever

MEFV: Mediterranean fever gene

PAAD: Pyrin-associated autoinflammatory disease

PAAND: Pyrin-associated autoinflammatory disease with neutrophilic dermatosis

PAPA: Pyogenic arthritis, pyoderma gangrenosum and acne

PFAPA: Periodic fever' apthous-stomatitis, cervical pharyngitis and adenitis

SAID: Systemic autoinflammatory disease

WES: Whole-exome sequencing

Familial Mediterranean fever (FMF) is a genetic disease characterized by recurrent fever and serositic attacks. It is the oldest known hereditary recurrent fever ${ }^{1,2}$ and the first systemic autoinflammatory 
disease (SAID) whose gene (MEFV for Mediterranean FeVer, NM_000243.2) has been identified., 4 The two decades that followed this discovery have been fruitful in clinical, genetic and functional developments, making FMF a unique and fascinating model for understanding this disease, and the innate immune defense in general. FMF usually begins at pediatric age and can be seen by a wide variety of pediatricians: generalists, rheumatologists, infectious disease specialists, gastroenterologists or dermatologists.

We will retrace the impressive scientific and medical journey that has switched a little-known rare disease gene into a field of intense interest leading from basic research to personalized medicine. We will explain how a gene initially identified from individuals meeting well-defined criteria (FMF) is now recognized as being at the origin of a wide and unanticipated range of clinical phenotypes jointly referred to as pyrin-associated autoinflammatory disease (PAAD).

The evolution of knowledge has led to a better interpretation of the impact of mutations in the various clinical pictures associated with the MEFV gene, resulting in increasingly relevant diagnoses.

\section{From benign paroxysmal peritonitis to FMF}

The various names given to FMF since its description in the early 1900 s reflect the main features of the disease. Historical cases of FMF were reviewed in a previous dedicated study. ${ }^{1}$ Figure 1 summarizes the key steps of the clinical and genetic discoveries in FMF. The first indisputable report of FMF was by Janeway, in 1908 (paroxysmal syndrome, with recurrent vomiting). ${ }^{5}$ Heller, in 1955, coined the current name "familial Mediterranean fever", ${ }^{2}$ which was recently validated by an international consortium for taxonomy and definition of autoinflammatory diseases. ${ }^{6}$

\section{From classical FMF to the clinical criteria for its diagnosis}

FMF is a recessive disease rare in Europe or USA, but relatively common in some populations of the Mediterranean basin, with prevalence of healthy carriers (ie, individuals carrying one pathogenic mutation) reaching up to one in five in Armenians. ${ }^{7}$ The estimated worldwide prevalence of FMF is 
120-150,000 patients. ${ }^{8}$ The classical FMF phenotype is characterized by self-limited and shortduration episodes of fever lasting 2 to 3 days. ${ }^{9}$ The mean age at disease onset is 4 years, but symptoms can occur as early as the first year of life or late in adulthood. Symptoms of acute inflammation include sterile peritonitis, pleural inflammation, arthritis, skin rashes, and elevated levels of acute phase reactants related to inappropriate secretion of interleukin 1 (IL)-1, IL-6 and tumor necrosis factor $\alpha(\mathrm{TNF} \alpha)$ reflecting the activation of the innate immune system. ${ }^{10}$ Absence of autoantibodies and auto-reactive $T$ cells denotes the absence of abnormal stimulation of adaptive immunity and provides an additional argument for recurrent autoinflammatory fever. Colchicine at an adequate dose and full compliance prevents inflammatory attacks and occurrence of renal AA amyloidosis in approximately $95 \%$ of cases. IL-1 blockers can be effective in refractory cases. ${ }^{11}$ FMF is diagnosed on a clinical basis and can be confirmed by genetic testing (see below). The most commonly used clinical criteria are those of Tel Hashomer, ${ }^{12}$ which are established in the Jewish adult population but also validated in children of other ethnicities. ${ }^{13}$ The Livneh criteria are also widely used, but they lack specificity in the pediatric population. ${ }^{14} \mathrm{~A}$ Turkish group has proposed new criteria for FMF diagnosis in children, ${ }^{15}$ which were validated in several ethnic groups. ${ }^{13,16}$ New, more comprehensive diagnostic criteria, are under development.

\section{From the clinic to genetics}

The observation of familial FMF cases fueled gene hunting in the early 1990s. The MEFV gene contains 10 exons and encodes the pyrin protein. Four founding mutations in exon 10 (p.M680I, p.M694I, p.M694V, and p.V726A) account for almost $80 \%$ of clinically and ethnically typical cases. ${ }^{7}$ To date, nearly 100 times more sequence variants have been recorded in the dedicated online database in fevers (https://infevers.umai-montpellier.fr/). ${ }^{17}$ Homozygosity for p.M694V confers the most severe phenotype (more joint and renal damage, earlier onset), ${ }^{18}$ whereas other low-penetrant variants such as p.E148Q in exon 2, are considered susceptibility factors for inflammation. ${ }^{19}$ 


\section{From classical recessive inheritance to possible dominance and}

\section{gene-dosage effect}

Initial familial segregation analyses demonstrated autosomal recessive inheritance, exacerbated by consanguinity, a cultural habit in Mediterranean countries. ${ }^{20}$ However, in about one-third of typical clinical cases, only one mutation is detected. ${ }^{21}$ The recognition of a large series of heterozygous individuals with a clinical picture of FMF supports that some single mutations (mainly in exon 10) may induce clinical signs. ${ }^{22}$ Many alternative explanations have been proposed, such as the existence of a second hit in another region of the gene or in another gene implicated in the regulatory pathways of the immune system, epigenetics or environmental factors, but none of these hypotheses have been definitely proven to date. The non-detection of a second mutation does not necessarily confirm a dominant transmission. True dominant transmission is rare in FMF and requires proof of segregation over several consecutive generations, i.e. that patients with overt disease do carry the pathogenic mutation, whereas asymptomatic individuals do not. Anecdotal cases of proven vertical transmission of p.M694/ ${ }^{23}$ and p.M694del in clinically ascertained FMF have been described (Table; available at www.jpeds.com), thus challenging the paradigm of pure recessive inheritance. ${ }^{24}$ ${ }^{25}$ A large study from an international database of patients with SAID (Eurofever) has provided clues to begin to understand this apparent contradiction. ${ }^{26}$ The authors highlighted a qualitative (severe mutations vs polymorphisms) and quantitative (2, 1, 0 mutations) molecular gradient paralleling the clinical picture (i.e., ranging from typical FMF to periodic fever, aphthous-stomatitis, cervical pharyngitis and adenitis (PFAPA), a disease for which no causative gene has been pinpointed). ${ }^{26}$ The authors suggested a dose effect (genetic dosage) involved in the phenotype and hypothesized that, under certain circumstances (e.g. presence of variants of still unidentified modifier genes), high penetrance MEFV mutations could give rise to symptom onset even in the presence of one wild-type allele. 


\section{From gene identification to the understanding of the Pyrin}

\section{function}

The apparently recessive nature of FMF has led to the postulation that the underlying molecular mechanism was a loss-of-function of the mutated pyrin. In asymptomatic carriers, the defective function of a mutated allele is compensated by the second wild-type allele and pathogenic mutations in each parental gene are classically necessary for the disease to be expressed. The demonstration that MEFV mutations are in fact gain-of-function reconverted this prevailing concept. ${ }^{27}$ The introduction of various exon 10 mutations into mouse pyrin (knock-in) induced a phenotype similar to human FMF, whereas deletion of mouse pyrin (knock-out) did not result in enhanced inflammation.

Pyrin is a key component of a specific inflammasome. ${ }^{28}$ Inflammasomes are multiprotein platforms leading to activation of the pro-inflammatory IL-1 and IL-18 following a pro-inflammatory event. ${ }^{29}$ RhoA GTPases regulate pyrin by activating serine-threonine kinases PKN1 and PKN2, which in turn, phosphorylate pyrin at two specific serines (S208 and S242 in humans). ${ }^{30,31}$ GTPase-mediated pyrin phosphorylation results in inhibitory binding by cellular 14-3-3 proteins (Figure 2). Upon toxin stimulation or bacterial infection, RhoA GTPases are inactivated, which leads to serine dephosphorylation, 14-3-3 dissociation, and subsequent pyrin inflammasome activation.

\section{From FMF to PAAD}

Patients with FMF criteria now benefit from the invaluable progress brought about by the discovery of the MEFV gene. However, sequencing of specific exons has sometimes revealed unusual phenotypes, variants and inheritance. For example, p.P369S and p.R408Q substitutions in exon 3, which most often come from the same parental chromosome (cis variant or complex allele), were associated with a highly variable phenotype, and were infrequently associated with typical FMF symptoms. ${ }^{32}$ The associated phenotypes included atypical FMF, ${ }^{32}$ PFAPA-like ${ }^{33}$ and entero-Behçet 
disease. ${ }^{34}$ In general, the patients are colchicine-responders. In a three-generation Spanish kindred, five affected members fulfilling the Tel-Hashomer criteria presented with a severe periodic inflammatory disorder segregating with the rare p.H478Y MEFV variant located in exon $5 .{ }^{35}$ Thus, the authors questioned whether this familial phenotype represented a case of unusual FMF phenotype or another MEFV-associated periodic inflammatory disorder because of its dominant inheritance, the prolonged febrile episodes, and the resistance to colchicine. Recently, next generation sequencing of a panel of known SAID genes or whole-exome sequencing (WES) facilitated the identification of new mutations and SAID genes but also yielded unexpected results. Two such examples are worth noting (Table and Figure 2). In a family of British descent with a colchicine-responsive autosomal-dominant periodic fever syndrome, WES sequencing was conducted and revealed a c.1730C $>A$ missense mutation in exon 8 resulting in the p.T577N substitution. ${ }^{36}$ Mutations at the same codon were found in three other individuals of various ethnic backgrounds. Their disorder was similar to FMF (fever, systemic inflammation, response to colchicine or IL-1 blockade) but somewhat distinct to it (inheritance pattern, duration of attacks lasting one week, evanescent urticaria-like skin rash). The authors hypothesized that mutations at codon 577 lead to a structural change significantly affecting pyrin function or oligomerisation. Dominant inheritance of genetic variants leading to p.T577N was also observed in a Japanese family with $\operatorname{PAAD}^{3} 7$ In individuals with severe neutrophilic dermatosis resembling pyogenic arthritis, pyoderma gangrenosum and acne (PAPA) syndrome WES investigations disclosed a dominant mutation within and in the immediate vicinity of the 14-3-3 protein pyrin binding domain (Table 1). ${ }^{38,39}$ This new pyrin-associated autoinflammatory disease with neutrophilic dermatosis was named PAAND. Only three PAAND families, all of European origin, have been reported so far: two harbored the p.S242R substitution and the third had the p.E244K substitution. Both mutations abolished the ability of 14-3-3 to bind pyrin, which resulted in a constitutive inflammasome formation. 


\section{Conclusion}

Pan-genomic approaches have revolutionized the identification of the pathophysiological pathways involved in SAID, an understanding of their regulation but also their better nosological classification. PAAD is an "umbrella" name chosen by the taxonomy committee to include all diseases caused by pyrin defects or MEFV mutations. ${ }^{6}$ This general term of PAAD was developed to link different subtypes of disorders of the same genetic origin. ${ }^{6}$ Butbul Aviel et al found that PFAPA (with and without FMF features) may be more common in patients from Mediterranean ancestry and suggested that the incidence and features of PFAPA may be influenced by the presence of the common MEFV variants. ${ }^{40}$ Association of MEFV variants with multifactorial disorders has often been reported (see review). ${ }^{41}$ However, these variants are thought to act as susceptibility factors with a weak individual effect, and cannot be considered as directly causative of the disease. Therefore, PFAPA does not belong to the PAAD family. In contrast, the molecular mechanism involving the MEFV gene as the cause of the disease is clearly established in PAAND which therefore represents a PAAD subtype. ${ }^{38}$

Comprehensive analysis of mutations in the MEFV gene revealed that symptom severity is associated with sequence variants in specific exons, at least in typical Armenian individuals. ${ }^{42}$ The exon in which the genetic variant is located also seems to affect the hereditary mode of transmission of the PAAD concerned, although the exact molecular mechanism underlying these observations remains elusive. Variable modes of transmission need to be considered for genetic counseling.

We have depicted the steps that led to the elucidation of the role of defective pyrin and have pinpointed the importance of the interpretation of mutations in less commonly affected exons, specifically in non-Mediterranean individuals, or in those in whom only one MEFV mutation has been detected. As a result, retro-phenotyping, which involves the molecular geneticist verifying the clinical presentation of the patient after the mutations have been identified to check for consistency, is becoming increasingly challenging. The reason is that quite often, genetic variants predicted as 
pathogenic based on familial segregation, mutation type, frequency in the general population, or in silico tools are found in genes that do not seem relevant to the phenotype of the patient. However, effective and targeted treatment depends on the correct genetic diagnosis.

\section{Acknowledgments}

We thank Laura Smales (biomedediting.com) for editing of English language.

\section{References}

1. Touitou I. New genetic interpretation of old diseases. Autoimmun Rev 2012;12:5-9.

2. Heller H, Kariv J, Sherf L, Sohar E. [Familial Mediterranean fever.]. Harefuah 1955;48:91-4.

3. TheFrenchFMFConsortium. A candidate gene for familial Mediterranean fever. Nat Genet 1997; 17:25-31.

4. ThelnternationalFMFConsortium. Ancient missense mutations in a new member of the RoRet gene family are likely to cause familial Mediterranean fever. Cell 1997;90:797-807.

5. Janeway $\mathrm{T}$, Mosenthal $\mathrm{H}$. An unusual paroxysmal syndrome, probably allied with recurrent vomiting, with a study of the nitrogen metabolism. Trans Assoc Am Physicians 1908;23:504-18.

6. Ben-Chetrit E, Gattorno M, Gul A, Kastner DL, Lachmann HJ, Touitou I, et al. Consensus proposal for taxonomy and definition of the autoinflammatory diseases (AIDs): a Delphi study. Ann Rheum Dis 2018;77:1558-65.

7. Touitou I. The spectrum of Familial Mediterranean Fever (FMF) mutations. Eur J Hum Genet 2001;9:473-83.

8. Ben-Chetrit E, Touitou I. Familial Mediterranean Fever in the world. Arthritis Rheum. 2009;61:1447-53.

9. Ben-Chetrit E, Levy M. Familial Mediterranean fever. Lancet 1998;351:659-64.

10. Yalcinkaya F, Cakar N, Acar B, Tutar E, Guriz H, Elhan AH, et al. The value of the levels of acute phase reactants for the prediction of familial Mediterranean fever associated amyloidosis: a case control study. Rheumatol Int 2007;27:517-22.

11. De Benedetti F, Gattorno M, Anton J, Ben-Chetrit E, Frenkel J, Hoffman HM, et al. Canakinumab for the Treatment of Autoinflammatory Recurrent Fever Syndromes. N Engl J Med 2018;378:1908-19.

12. Sohar E, Gafni G, Pras M. Tel Hashomer key to severity scores for FMF. In: Sohar E, Gafni G, Pras M (Eds). Proceedings of the First International Conference on FMF. Freund Publishing House, London and Tel Aviv 1997:208.

13. Kondi A, Hentgen V, Piram M, Letierce A, Guillaume-Czitrom S, Kone-Paut I. Validation of the new paediatric criteria for the diagnosis of familial Mediterranean fever: data from a mixed population of 100 children from the French reference centre for auto-inflammatory disorders. Rheumatology (Oxford) 2010;49:2200-3.

14. Livneh A, Langevitz P, Zemer D, Zaks N, Kees S, Lidar T, et al. Criteria for the diagnosis of familial Mediterranean fever. Arthritis Rheum 1997;40:1879-85.

15. Yalcinkaya F, Ozen S, Ozcakar ZB, Aktay N, Cakar N, Duzova A, et al. A new set of criteria for the diagnosis of familial Mediterranean fever in childhood. Rheumatology (Oxford) 2009;48:395-8.

16. Demirkaya E, Saglam C, Turker T, Kone-Paut I, Woo P, Doglio M, et al. Performance of Different Diagnostic Criteria for Familial Mediterranean Fever in Children with Periodic Fevers: Results from a Multicenter International Registry. J Rheumatol 2015;43:154-60. 
17. Milhavet F, Cuisset L, Hoffman HM, Slim R, El-Shanti H, Aksentijevich I, et al. The infevers autoinflammatory mutation online registry: update with new genes and functions. Hum Mutat 2008;29:803-8.

18. Grossman C, Kassel Y, Livneh A, Ben-Zvi I. Familial Mediterranean fever (FMF) phenotype in patients homozygous to the MEFV M694V mutation. Eur J Med Genet 2018.

19. Marek-Yagel D, Bar-Joseph I, Pras E, Berkun Y. Is E148Q a benign polymorphism or a diseasecausing mutation? J Rheumatol 2009;36:2372.

20. Rogers DB, Shohat M, Petersen GM, Bickal J, Congleton J, Schwabe AD, et al. Familial Mediterranean fever in Armenians: autosomal recessive inheritance with high gene frequency. Am J Med Genet 1989;34:168-72.

21. Jeru I, Hentgen V, Cochet E, Duquesnoy P, Le Borgne G, Grimprel E, et al. The risk of familial Mediterranean fever in MEFV heterozygotes: a statistical approach. PLoS One 2013;8:e68431.

22. Hentgen V, Grateau G, Stankovic-Stojanovic K, Amselem S, Jeru I. Familial Mediterranean fever in heterozygotes: are we able to accurately diagnose the disease in very young children? Arthritis Rheum 2013;65:1654-62.

23. Booth DR, Gillmore JD, Lachmann HJ, Booth SE, Bybee A, Soyturk M, et al. The genetic basis of autosomal dominant familial Mediterranean fever. QJM 2000;93:217-21.

24. Fukushima Y, Obara K, Hirata H, Sugiyama K, Fukuda T, Takabe K. Three Japanese patients (mother and two children) with familial Mediterranean fever associated with compound heterozygosity for L110P/E1480/M694I and an autosomal true dominant inheritance pattern. Asian Pac J Allergy Immunol 2014;31:325-9.

25. Rowczenio DM, lancu DS, Trojer H, Gilbertson JA, Gillmore JD, Wechalekar AD, et al. Autosomal dominant familial Mediterranean fever in Northern European Caucasians associated with deletion of p.M694 residue-a case series and genetic exploration. Rheumatology (Oxford) 2016;56:209-13.

26. Federici S, Calcagno G, Finetti M, Gallizzi R, Meini A, Vitale A, et al. Clinical impact of MEFV mutations in children with periodic fever in a prevalent western European Caucasian population. Ann Rheum Dis 2012;71:1961-5.

27. Chae JJ, Cho YH, Lee GS, Cheng J, Liu PP, Feigenbaum L, et al. Gain-of-function Pyrin mutations induce NLRP3 protein-independent interleukin-1beta activation and severe autoinflammation in mice. Immunity 2011;34:755-68.

28. Park YH, Wood G, Kastner DL, Chae JJ. Pyrin inflammasome activation and RhoA signaling in the autoinflammatory diseases FMF and HIDS. Nat Immunol 2016;17:914-21.

29. Harapas CR, Steiner A, Davidson S, Masters SL. An Update on Autoinflammatory Diseases: Inflammasomopathies. Curr Rheumatol Rep 2018;20:40.

30. Gao W, Yang J, Liu W, Wang Y, Shao F. Site-specific phosphorylation and microtubule dynamics control Pyrin inflammasome activation. Proc Natl Acad Sci U S A 2016;113:E4857-66.

31. Xu H, Yang J, Gao W, Li L, Li P, Zhang L, et al. Innate immune sensing of bacterial modifications of Rho GTPases by the Pyrin inflammasome. Nature 2014;513:237-41.

32. Ryan JG, Masters SL, Booty MG, Habal N, Alexander JD, Barham BK, et al. Clinical features and functional significance of the P369S/R408Q variant in pyrin, the familial Mediterranean fever protein. Ann Rheum Dis 2010;69:1383-8.

33. Yamagami K, Nakamura T, Nakamura R, Hanioka Y, Seki K, Chiba H, et al. Familial Mediterranean fever with P369S/R408Q exon 3 variant in pyrin presenting as symptoms of PFAPA. Mod Rheumatol 2017;27:356-9.

34. Fujikawa K, Migita K, Nagasato A, Tsukada T, Kawakami A, Equchi K. Mediterranean fever (MEFV) variant P369S/R408Q in a patient with entero-Behçet's disease who successfully responded to treatment with colchicine. Intern Med 2014;53:2381-4.

35. Aldea A, Campistol JM, Arostegui JI, Rius J, Maso M, Vives J, et al. A severe autosomaldominant periodic inflammatory disorder with renal AA amyloidosis and colchicine resistance associated to the MEFV H478Y variant in a Spanish kindred: an unusual familial Mediterranean fever 
phenotype or another MEFV-associated periodic inflammatory disorder? Am J Med Genet A 2004;124:67-73.

36. Stoffels M, Szperl A, Simon A, Netea MG, Plantinga TS, van Deuren M, et al. MEFV mutations affecting pyrin amino acid 577 cause autosomal dominant autoinflammatory disease. Ann Rheum Dis 2013;73:455-61.

37. Nakaseko H, Iwata N, Izawa K, Shibata H, Yasuoka R, Kohagura T, et al. Expanding clinical spectrum of autosomal dominant pyrin-associated autoinflammatory disorder caused by the heterozygous MEFV p.Thr577Asn variant. Rheumatology (Oxford) 2018.

38. Masters SL, Lagou V, Jeru I, Baker PJ, Van Eyck L, Parry DA, et al. Familial autoinflammation with neutrophilic dermatosis reveals a regulatory mechanism of pyrin activation. Sci Transl Med 2016;8:332ra45.

39. Moghaddas F, Llamas R, De Nardo D, Martinez-Banaclocha H, Martinez-Garcia JJ, Mesa-DelCastillo $P$, et al. A novel Pyrin-Associated Autoinflammation with Neutrophilic Dermatosis mutation further defines 14-3-3 binding of pyrin and distinction to Familial Mediterranean Fever. Ann Rheum Dis 2017;76:2085-94.

40. Butbul Aviel Y, Harel L, Abu Rumi M, Brik R, Hezkelo N, Ohana O, et al. Familial Mediterranean Fever Is Commonly Diagnosed in Children in Israel with Periodic Fever Aphthous Stomatitis, Pharyngitis, and Adenitis Syndrome. J Pediatr 2018.

41. Touitou I. Inheritance of autoinflammatory diseases: shifting paradigms and nomenclature. J Med Genet 2013;50:349-59.

42. Moradian MM, Babikyan D, Banoian D, Hayrapetyan H, Manvelyan H, Avanesian N, et al. Comprehensive analysis of mutations in the MEFV gene reveal that the location and not the substitution type determines symptom severity in FMF. Mol Genet Genomic Med 2017;5:742-50. 


\section{Legends to figures}

Figure 1: Key milestones of the clinical and genetic discoveries in familial Mediterranean fever (FMF)

Three main periods can be delineated. The first steps were clinical (in red), basically devoted to the disease description, with definitive naming and clinical criteria as key events. The second important period required both clinical and genetic investigations (in purple). Identification of the FMF gene and its protein pyrin was the "diamond" of 1997. The last decade (in blue) saw the advent of high throughput sequencing approaches pinpointing pyrin as being involved in many more phenotypes described under the "umbrella" pyrin-associated autoinflammatory disease (PAAD). The unraveling of the normal pyrin function as well as the demonstration that mutations are gain of function with gene dosage helped in understanding the clinical spectrum of PAAD.

PAAND: pyrin-associated autoinflammatory disease with neutrophilic dermatosis

Figure 2: Schematic representation of the pyrin protein and mutations resulting in pyrin-associated autoinflammatory disease (PAAD)

The B30.2 domain contains the most common pathogenic familial Mediterranean (FMF) mutations, which classically result in autosomal recessive FMF. Dominant mutations in exons 5, 8 and 10 are responsible for FMF-like and non-FMF PAAD. The precise molecular mechanism involved in these PAADs is still mainly unsolved. In contrast, dominant mutations in exon 2 in or close to the 14-3-3 binding domain are now known to impair binding of 14-3-3 to phosphorylated pyrin and trigger spontaneous pyrin-inflammasome formation, resulting in pyrin-associated autoinflammatory disease with neutrophilic dermatosis (PAAND). Ex: Exon. 


\begin{tabular}{|c|c|c|c|c|c|c|c|c|c|c|c|c|}
\hline \multirow[b]{3}{*}{$\begin{array}{l}\text { Origin } \\
\text { ( } \mathrm{N} \text { families } \\
; \mathrm{N} \text { relatives) }\end{array}$} & \multicolumn{12}{|c|}{ Dominant Pyrin-associated autoinflammatory disease (PAAD) } \\
\hline & \multicolumn{5}{|c|}{ Typical FMF } & \multicolumn{5}{|c|}{ Periodic fever with autoinflammatory disease* } & \multicolumn{2}{|r|}{ PAAND } \\
\hline & Mediterranean & $\begin{array}{l}\text { Indian } \\
(1 ; 5) \\
\text { Turkish } \\
(1 ; 8)\end{array}$ & $\begin{array}{l}\text { British } \\
(1 ; 2)\end{array}$ & $\begin{array}{l}\text { Japanese } \\
(1 ; 3)\end{array}$ & $\begin{array}{l}\text { Northern- } \\
\text { Europe*** } \\
(4 ; 10)\end{array}$ & $\begin{array}{l}\text { Spanish } \\
(1 ; 5)\end{array}$ & $\begin{array}{l}\text { British } \\
(1 ; 7)\end{array}$ & $\begin{array}{l}\text { Turkish } \\
(1 ; 8)\end{array}$ & $\begin{array}{l}\text { Dutch } \\
(1 ; 3)\end{array}$ & $\begin{array}{l}\text { Japanese } \\
(1 ; 3)\end{array}$ & $\begin{array}{l}\text { Belgium } \\
(1 ; 12)\end{array}$ & $\begin{array}{l}\text { British } \\
(1 ; 2)\end{array}$ \\
\hline Exon & 10 & 10 & 10 & 10 & 10 & 5 & 8 & 8 & 8 & 8 & 2 & 2 \\
\hline $\begin{array}{l}\text { Mutation(s) } \\
\text { *** }\end{array}$ & $\begin{array}{l}\text { p.M694V } \\
\text { (c.2080A>G) } \\
\text { most frequent }\end{array}$ & $\begin{array}{l}\text { p.M694I } \\
\text { (c.2082G }>A)\end{array}$ & $\begin{array}{l}\text { M694del } \\
\text { (c.2081_2083del) }\end{array}$ & $\begin{array}{l}\text { p.M694I } \\
\text { (c.2082G>A) }\end{array}$ & $\begin{array}{l}\text { M694del } \\
\text { (c.2081_2083del) }\end{array}$ & $\begin{array}{l}\text { p.H478Y } \\
(\text { c. } 1432 \mathrm{C}>\mathrm{T})\end{array}$ & $\begin{array}{l}\text { p.T577N } \\
\text { (c.1730C>A) }\end{array}$ & $\begin{array}{l}\text { p.T577S } \\
(\text { c. } 1730 \mathrm{C}>\mathrm{G})\end{array}$ & $\begin{array}{l}\text { p.T577A } \\
(\text { c.1729A>G) }\end{array}$ & $\begin{array}{l}\text { p.T577N } \\
(\text { c.1730C }>A)\end{array}$ & $\begin{array}{l}\text { p.S242R } \\
(\text { c. } 726 C>G)\end{array}$ & $\begin{array}{l}\text { p.S242R } \\
(\text { c. } 726 C>G)\end{array}$ \\
\hline Age at onset & childhood & Typical & Typical & $7-30$ & $6-35$ & $9-13$ & $6-10$ & ND & ND & $3-16$ & childhood & ND \\
\hline $\begin{array}{l}\text { Attack } \\
\text { duration }\end{array}$ & 2-4 days & Typical & Typical & ND & 2.5-6 days & 6-12 days & $\begin{array}{l}\text { Days to } \\
\text { weeks }\end{array}$ & $1-1.5$ weeks & weeks & $\begin{array}{l}\text { 1day-6 } \\
\text { months }\end{array}$ & $\begin{array}{l}\text { Several } \\
\text { weeks }\end{array}$ & ND \\
\hline Fever & Yes & Typical & Typical & Yes & $\begin{array}{l}8 / 10 \text { alive } \\
\text { patients }\end{array}$ & Yes & Yes & Yes & Yes & $\begin{array}{l}\text { No or low } \\
\text { grade }\end{array}$ & Yes & Yes \\
\hline Serositis & Yes & Typical & Typical & Yes & Yes & Yes & Yes & Yes & Arthritis & Peritonitis & No & No \\
\hline Skin lesions & $\begin{array}{l}\text { Erysypelas- } \\
\text { like erythema }\end{array}$ & Typical & Typical & No & $\begin{array}{l}\text { Erysypeloid } \\
\text { erythema in 2/13 } \\
\text { patients }\end{array}$ & Erysipelas & $\begin{array}{l}\text { Evanescent } \\
\text { urticaria-like } \\
\text { skin rash }\end{array}$ & No & $\begin{array}{l}\text { Evanescent } \\
\text { urticaria-like } \\
\text { skin rash }\end{array}$ & No & $\begin{array}{l}\text { Neutrophilic } \\
\text { dermatosis }\end{array}$ & $\begin{array}{l}\text { Neutrophilic } \\
\text { dermatosis }\end{array}$ \\
\hline $\begin{array}{l}\text { Response to } \\
\text { colchicine }\end{array}$ & Yes & Yes & Yes & Yes & Yes & No & Yes & Yes & No & Yes or ND & ND & ND \\
\hline $\begin{array}{l}\text { Biological } \\
\text { inflammation }\end{array}$ & Yes & Typical & Typical & Yes & Yes & Yes & ND & ND & ND & Yes or ND & Yes & Yes \\
\hline Reference & & 22 & 22 & 23 & 24 & 34 & 35 & 35 & 35 & 36 & 37 & 37 \\
\hline
\end{tabular}

FMF: familial Mediterranean fever; ND: not determined

* A patient harboring a c.1729A>T (p.T577S) mutation was also detected in a Dutch patient with an autoinflammatory phenotype but no familial nor clinical data was available

** Sporadic patients described in this paper are not shown as dominant transmission is not ascertained

*** E148Q was detected in some patients but is not mentioned as it is now recognized as a variant of unknown significance 


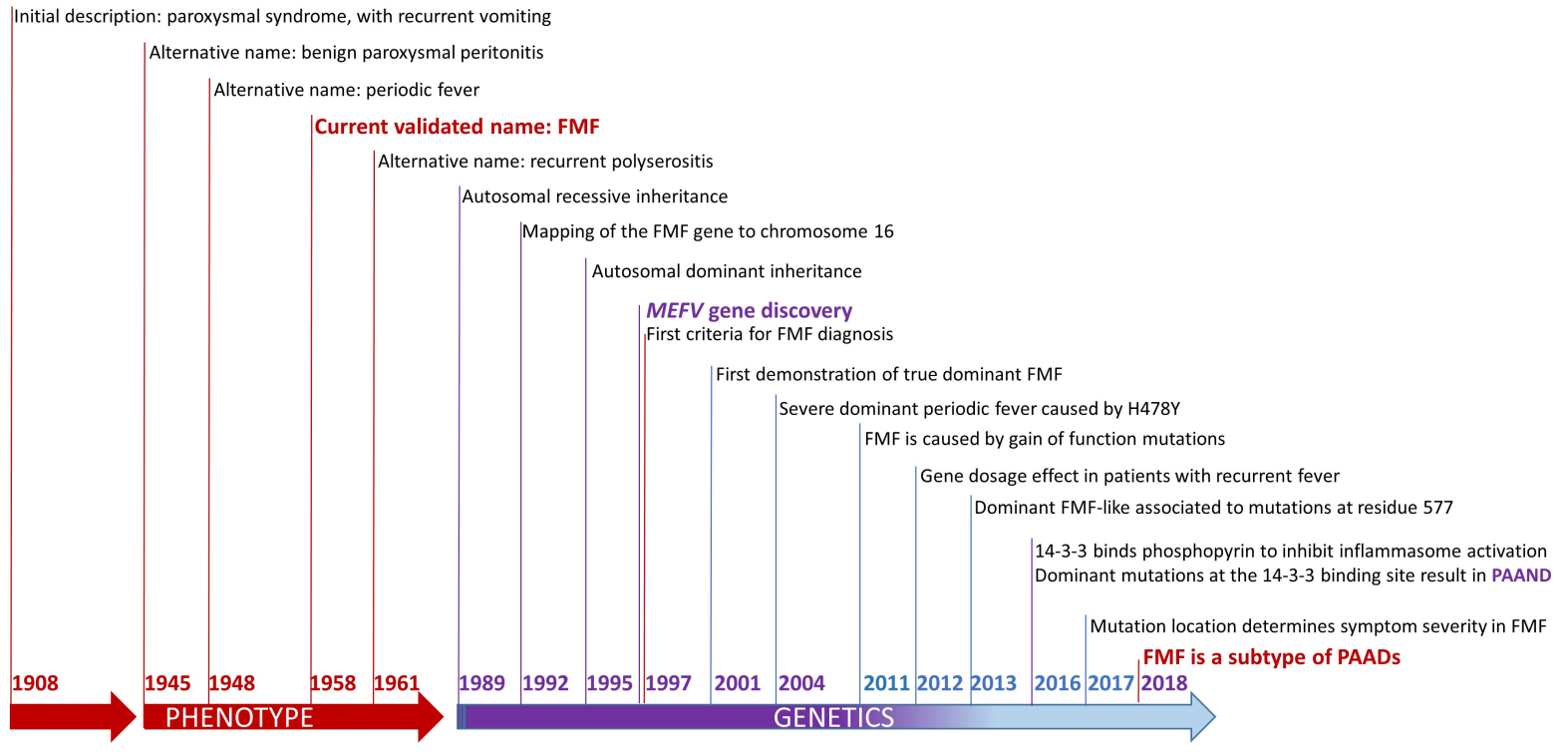


Pyrin-associated autoinflammatory disease (PAAD)

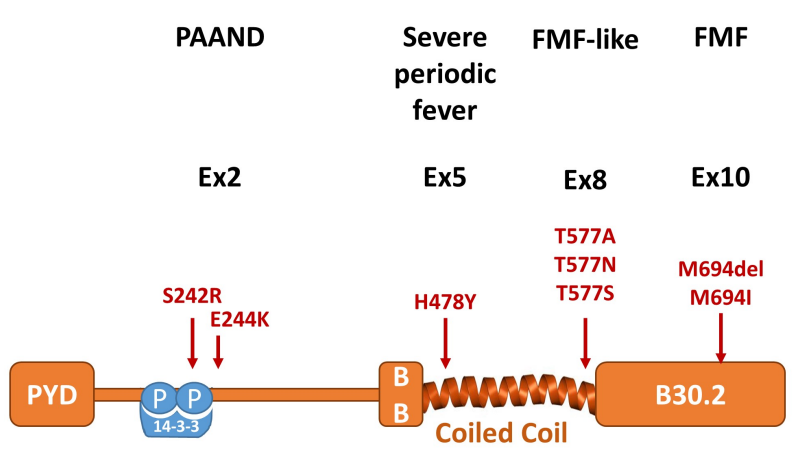

